\title{
Prevalence of the BRCA1 founder mutation c.5266dupin Brazilian individuals at-risk for the hereditary breast and ovarian cancer syndrome
}

Ingrid P Ewald ${ }^{1,2}$, Patrícia Izetti ${ }^{1,3}$, Fernando R Vargas ${ }^{4,5}$, Miguel AM Moreira ${ }^{5,6}$, Aline S Moreira ${ }^{5,6}$, Carlos A Moreira-Filho ${ }^{7}$, Danielle R Cunha ${ }^{8}$, Sara Hamaguchi ${ }^{8}$, Suzi A Camey ${ }^{9}$, Aishameriane Schmidt ${ }^{9}$, Maira Caleffi ${ }^{10}$, Patrícia Koehler-Santos ${ }^{1,2}$, Roberto Giugliani ${ }^{2,11,12,13}$ and Patricia Ashton-Prolla ${ }^{1,2,3,11,12,13^{*}}$

\begin{abstract}
About $5-10 \%$ of breast and ovarian carcinomas are hereditary and most of these result from germline mutations in the BRCA1 and BRCA2 genes. In women of Ashkenazi Jewish ascendance, up to $30 \%$ of breast and ovarian carcinomas may be attributable to mutations in these genes, where 3 founder mutations, c.68_69del (185delAG) and c.5266dup (5382insC) in BRCA1 and c.5946del (6174delT) in BRCA2, are commonly encountered. It has been suggested by some authors that screening for founder mutations should be undertaken in all Brazilian women with breast cancer. Thus, the goal of this study was to determine the prevalence of three founder mutations, commonly identified in Ashkenazi individuals in a sample of non-Ashkenazi cancer-affected Brazilian women with clearly defined risk factors for hereditary breast and ovarian cancer (HBOC) syndrome. Among 137 unrelated Brazilian women from HBOC families, the BRCA1c.5266dup mutation was identified in seven individuals (5\%). This prevalence is similar to that encountered in non-Ashkenazi $\mathrm{HBOC}$ families in other populations. However, among patients with bilateral breast cancer, the frequency of c.5266dup was significantly higher when compared to patients with unilateral breast tumors (12.1\% vs 1.2\%, $p=0.023)$. The BRCA1 c.68_69del and BRCA2 c.5946del mutations did not occur in this sample. We conclude that screening non-Ashkenazi breast cancer-affected women from the ethnically heterogeneous Brazilian populations for the BRCA1 c.68_69del and BRCA2 c.5946del is not justified, and that screening for BRCA1c.5266dup should be considered in high risk patients, given its prevalence as a single mutation. In high-risk patients, a negative screening result should always be followed by comprehensive $B R C A$ gene testing. The finding of a significantly higher frequency of BRCA1 c.5266dup in women with bilateral breast cancer, as well as existence of other as yet unidentified founder mutations in this population, should be further assessed in a larger well characterized high-risk cohort.
\end{abstract}

Keywords: Hereditary breast cancer, Hereditary breast and ovarian cancer Syndrome, Founder mutations, BRCA1 gene, BRCA2 gene

\section{Introduction}

Breast cancer is the most common non-cutaneous malignancy in Brazilian women of all ages. In the Southern and Southeastern States of Brazil, the estimated breast cancer incidence rates for 2010 reached 64.54 and 64.30 per 100,000 women, the highest in the country [1].

\footnotetext{
* Correspondence: pprolla@hcpa.ufrgs.br

'Laboratório de Medicina Genômica, Centro de Pesquisa Experimental Hospital de Clínicas de Porto Alegre. Rua Ramiro Barcelos 2350. 90035-903. Porto Alegre, RS. Brazil

Full list of author information is available at the end of the article
}

In spite of continuous efforts to improve early detection and treatment, breast cancer remains the leading cause of deaths by cancer in Brazilian women. Furthermore, mortality rates by this type of cancer are still increasing in the Southern States of the country $[2,3]$.

It is estimated that $5-10 \%$ of breast cancers are hereditary, arising from highly penetrant germline mutations in cancer predisposition genes [4]. A significant proportion of individuals with hereditary breast cancer have mutations in the tumor suppressor genes BRCA1 (OMIM \# 113705) and BRCA2 (OMIM \# 600185) [5]. Carriers of

\section{() Biomed Central}


such mutations are usually predisposed to breast, ovarian, prostate and other cancers at an early age, a syndrome known as Hereditary Breast and Ovarian Cancer (HBOC) [6].

$B R C A 1$ and $B R C A 2$ are similar in their structure and quite large (100 and $70 \mathrm{~kb}$, respectively). Germline mutations in these genes are usually point mutations, and are scattered along their entire coding sequences; mutational hot-spots are uncommon. Deleterious gene rearrangements may also occur in up to $30 \%$ of the cases [7]. Therefore, full gene sequencing and rearrangement testing is warranted for accurate diagnosis in most individuals. In a few populations, however, founder mutations have been described and are responsible for a significant proportion of the mutation-positive diagnoses. This is the case for the c.68_69del and c.5266dup mutations in $B R C A 1$ and c.5946del mutation in BRCA2 (until recently referred in the literature as $185 \mathrm{delAG}, 5382 \mathrm{ins} C$ and $6174 \mathrm{delT}$, respectively) which are found in $10-12 \%$ of Ashkenazi Jewish women diagnosed with breast cancer $[8,9]$. BRCA gene founder mutations have also been described in other populations, including the Slavic (BRCA1c.5266dup mutation) [10,11], Finnish and Icelandic (BRCA2999del5 mutation) and German populations (BRCA1delexon17) [12,13]. In these populations, initial screening of a clinically suspicious case by testing for founder mutations is acceptable and allows the diagnosis of a significant number of carriers using fast and straightforward methodologies at a lower cost [14].

In a recent study done in the Brazilian State of Rio de Janeiro [15], 402 unrelated non-Ashkenazi women affected with breast cancer were screened for the three Ashkenazi founder mutations. Of the nine mutation-positive individuals identified, five (56\%) harbored the BRCA1c.5266dup mutation in exon 20 and the overall prevalence of this particular mutation in the sample studied was $1.24 \%$. The women enrolled in the study were not selected for a family history of the disease, and their ancestry was not described. A previous study [16] of 47 unrelated breast cancer-affected women from Rio de Janeiro with a family history of cancer suggestive of the HBOC syndrome had already identified the BRCA1c.5266dup mutation in a significant proportion of the mutation-positive patients (four in seven). Interestingly, none of them reported Jewish ancestry. Finally, Simon et al. [17] reported the occurrence of the BRCA1c.5266dup mutation in Jewish and non-Jewish HBOC families from the Brazilian State of São Paulo. Recently, Hamel et al. [18] have studied the c.5266dupC in 14 different population groups (Russian, Latvian, Ukrainian, Czech, Slovak, Polish, Danish, Dutch, French, German, Italian, Greek, Brazilian and AJ) and confirmed that all carriers of this mutation share a common haplotype proposing that it arose approximately 1800 years ago in either Scandinavia or northern Russia and subsequently spread to the various populations, including the Ashkenazi Jewish population.

Considering the importance of identifying mutationpositive $\mathrm{HBOC}$ patients for genetic counseling purposes and the previous reports indicating that founder mutations, in particular BRCA1c.5266dup, may be common in Brazilian patients diagnosed with breast cancer, we performed this study with the aim of determining the frequency of these mutations in non-Ashkenazi individuals diagnosed with cancer and whose families fulfilled clinical criteria for the HBOC syndrome.

\section{Patients and Methods}

A consecutive sample of 137 unrelated Brazilian patients, self-referred as non-Ashkenazi and with a significant personal and/or family history of hereditary breast and ovarian cancer, was evaluated at cancer genetic counseling services from the two regions with the highest breast cancer incidence rates in the country in Southern and Southeastern Brazil: Porto Alegre (from the Cancer Genetics Clinic of Hospital de Clínicas de Porto Alegre) and Rio de Janeiro, (from INCA, the Brazilian National Cancer Institute). All patients confirmed residence in the States from which they were recruited for at least ten years, had been diagnosed with cancer or were cancer unaffected individuals likely to be obligate carriers of $B R C A$ mutations. A significant family history of HBOC was defined as presence of either: (a) the American Society of Clinical Oncology (ASCO) criteria for HBOC [19] or (b) a prior probability of harboring a $B R C A$ mutation $\geq 30 \%$ by pedigree analysis using the Myriad mutation prevalence tables or the Penn II mutation prediction model [20-22]. Women diagnosed with bilateral breast cancer under the age of 50 years, regardless of family history, were also included. All patients relied exclusively on the public health care system through which $B R C A 1$ and $B R C A 2$ full gene sequencing is currently not available, even for patients of very high genetic risk. After signature of informed consent, genomic DNA was extracted from peripheral blood by conventional methods [23] and screening for the founder mutations was performed by PCR-amplification and DNA sequencing in both directions using the DYEnamic ET Terminator Cycle Sequencing Kit and the MegabaseorABI automated sequencers. The amplification and sequencing primer sequences used were: (a) for BRCA1 exon 2 (c.68_69del mutation): 5'GTTCTTTGGTTTGTATTATTCT-3' and 5'-AGAGGC AGAGTGGATGGA-3'; (b) for BRCA1 exon 20 (c.5266dup mutation): 5'-ATATGACGTGTCTGCTCCAC-3' and 5'-GGGAATCCAAATTACACAGC-3'. and (c) for BRCA2exon 11 (c.5946del mutation): 5'-AACGA AAATTATGGCAGGTTGTTAC-3' and 5'-GCTTTC CACTTGCTGTACTAAATCC-3'. All mutation-positive samples were confirmed in a second independent 
analysis. The amplification and sequencing protocols are available upon request.

\section{Statistical Analyses}

Sample size for this study was estimated using WINPEPI (PEPI-for-Windows). SPSS version 18.0 was used for data handling and statistical analyses. For descriptive analysis, categorical variables were described by their absolute and/ or relative frequencies and quantitative variables were expressed as mean and standard deviation (SD). The existence of an association between categorical variables was examined by chi-square. Association between bilateral breast cancer and the c.5266dup mutation in a subgroup analysis of patients with breast cancer were analyzed by Fishers' exact test. A significance level of 0.05 was adopted.

\section{Results}

Sample characteristics are described in Table 1. The mean age at cancer diagnosis (all types) was 43.4 years $(\mathrm{SD}=$ 10.1; range: 24-73 years). Among the 137 probands included in the study, 42 (31.0\%) were recruited in Porto Alegre and 95 (69.0\%) in Rio de Janeiro.

Most patients $(n=126,91.9 \%)$ had been diagnosed with breast cancer and of these, $110(80.3 \%)$ were diagnosed under the age of 50 years. Five patients had been diagnosed with tumors other than breast and ovarian cancer (colorectal cancer, melanoma, gastric cancer, esophageal cancer, endometrial cancer), but were included because they had a significant family history of breast and ovarian cancer in first and second degree relatives. The only cancer-unaffected patient in this study was considered an

Table 1 Clinical description of the sample studied $(n=137)$

\begin{tabular}{|c|c|c|c|}
\hline Characteristic & $\mathbf{N}$ & $\%$ & Mean (SD) \\
\hline \multicolumn{4}{|l|}{ Sex } \\
\hline Female & 134 & 97.8 & \\
\hline Male & 3 & 2.2 & \\
\hline Age at breast cancer (years)* & & & 42.3 (8.3) range: $24-73$ \\
\hline \multicolumn{4}{|l|}{ Inclusion criteria } \\
\hline ASCO & 113 & 82.5 & \\
\hline Probability of mutation (Myriad) $\geq 30 \%$ & 62 & 45.3 & \\
\hline Probability of mutation (PENN II model) $\geq 30 \%$ & 28 & 20.4 & \\
\hline Bilateral breast cancer & 34 & 24.8 & \\
\hline \multicolumn{4}{|l|}{ Cancer history in the proband $(n=136)^{* *}$} \\
\hline \multicolumn{4}{|l|}{ One primary tumor } \\
\hline Breast cancer & 85 & 62.5 & \\
\hline Ovarian cancer & 4 & 2.9 & \\
\hline Other\# & 5 & 3.7 & \\
\hline \multicolumn{4}{|l|}{ Multiple primaries: } \\
\hline$\geq 2$ Breast & 31 & 22.8 & \\
\hline$\geq 2$ ovarian & 0 & 0 & \\
\hline 1 breast and 1 ovarian & 2 & 1.5 & \\
\hline$\geq 2$ Breast and 1 ovarian & 3 & 2.2 & \\
\hline At least one breast + other & 5 & 3.7 & \\
\hline At least one ovarian + other & 1 & 0.7 & \\
\hline \multicolumn{4}{|l|}{ Criteria for multiple hereditary cancer syndromes } \\
\hline HBOC + Li-FraumeniLike (Eeles criteria) & 23 & 16.8 & \\
\hline HBOC + Li-Fraumeni Like (Birch criteria) & 2 & 1.4 & \\
\hline HBOC + Hereditary Breast and Colorectal Cancer & 14 & 10.2 & \\
\hline HBOC + Hereditary Non-Polyposis Colorectal Cancer & 3 & 2.2 & \\
\hline \multicolumn{4}{|l|}{ Cancer family history ( $1^{\text {st }}$ and $2^{\text {nd }}$ degree relatives) } \\
\hline Number of breast cancer cases & & & $3.3(1.52)$ \\
\hline Number of ovarian cancer cases & & & $1.3(0.61)$ \\
\hline Age at first breast cancer & & & $44.2(6.8)$ \\
\hline
\end{tabular}

*In women with multiple breast cancers, age at the diagnosis of the first primary was considered.

**One patient was cancer unaffected. In the sample of 136 cancer affected probands, there were a total of 184 tumors, including synchronous and metachronous cases.

\#(colorectal, melanoma, gastric, uterine cervix, esophagus, endometrium) 
obligate carrier due to a significant history of breast cancer in the parental and offspring generations.

Approximately $30.7 \%$ of the patients had synchronous or metachronous multiple primary tumors $(n=42)$ and the mean age at first cancer diagnosis in this group was 41.5 years ( $\mathrm{SD}=6.9$; range: $28-61$ years). Approximately onefourth of the total participants had bilateral breast cancer $(\mathrm{n}=34)$, and the mean age at the first primary tumor in this group was 42.2 years ( $\mathrm{SD}=7.2$; range $28-61$ years), similar to the mean age in patients with only one primary breast cancer ( 42.3 years; $\mathrm{SD}=8.8$; range $24-73$ ).

For the entire sample, $45.3 \%$ and $20.4 \%$ had an estimated probability of a $B R C A$ gene mutation equal or greater than $30.0 \%$ using the Myriad prevalence tables and the Penn II model, respectively. The mean prior probability of carrying a BRCA mutation using either method was similar: $24.4 \%$ using the Myriad tables ( $\mathrm{SD}=3.4$, range, 2.8-67.2\%) and $22.9 \%$ using Penn II (SD = 15.1, range, 7-93\%).

Overall, a germline mutation was identified in seven (5.0\%) of the 137 patients studied and in all of them, it consisted of the c.5266dup mutation in exon 20 of the $B R C A 1$ gene. A more detailed description of the mutation-positive cases is shown in Table 2. The other founder mutations (c.68_69del in BRCA1 and c.5946del in $B R C A 2$ ) were not identified. If only breast or ovarian cancer-affected probands are considered, the BRCA1c.5266dup frequency remains similar, 5.3\% (7/ 131).

Patients diagnosed with bilateral breast cancer were more likely to carry the BRCA1c.5266dup mutation than patients with unilateral breast cancer (BRCA1c.5266dup was present in 4 of 34 patients with bilateral breast cancer vs. 1 of 82 unilateral breast cancer patients; $p=$ $0.023)$. In addition, $B R C A 1$ c.5266dup carriers with bilateral breast cancer were younger when first diagnosed (mean age 38 years; $\mathrm{SD}=6$; range 33-47) than non-carriers (43 years; $\mathrm{SD}=7$; range $28-61$ ) although this difference did not reach significance $(p=0.189)$.

Two of the four metachronous breast cancer mutation carriers had no family history of breast or ovarian cancer and did not fulfill any other inclusion criteria of the study, apart from the early onset bilateral breast cancer diagnosis. Both cases, however, had a limited family structure (fewer than 2 first- or second-degree female relatives alive and at an age $\geq 45$ years in either lineage) as defined by Weitzel et al. [24].

Families from the Southern region had a significantly higher number of breast cancer diagnoses in the family than those from the Southeast (4.0 in versus 3.1, $p=$ 0.004). However, there was no significant difference in the mean age of breast cancer diagnosis (40.4 and 42.8 years, respectively, $p=0.206$ ), nor in BRCA1c.5266dup frequency ( $3.8 \%$ and $4.5 \%$, respectively, $\mathrm{p}>0.999$ ) between regions.

\section{Discussion}

The identification of individuals at-risk for hereditary breast cancer is important to ensure that appropriate risk reducing interventions are offered, to counsel patients and families regarding recurrence risk and to guide the decisions about cancer treatment interventions in affected individuals. The precise identification of at-risk individuals in a given family depends on the

Table 2 Detailed description of BRCA1c.5266dup-positive probands and their families

\begin{tabular}{|c|c|c|c|c|c|c|c|}
\hline \multirow[b]{2}{*}{$\begin{array}{c}\text { Case } \\
\#\end{array}$} & \multirow[b]{2}{*}{$\begin{array}{c}\text { Cancer } \\
\text { diagnosis } \\
\text { (index-case) }\end{array}$} & \multirow[b]{2}{*}{$\begin{array}{l}\text { Age at } \\
\text { diagnosis } \\
\text { (ys) }\end{array}$} & \multirow[b]{2}{*}{ Cancer family history* } & \multirow[b]{2}{*}{$\begin{array}{l}\text { ASCO } \\
\text { criteria }\end{array}$} & \multirow[b]{2}{*}{$\begin{array}{l}\text { Limited } \\
\text { Family } \\
\text { Structure }\end{array}$} & \multicolumn{2}{|c|}{$\begin{array}{l}\text { Prior Probability of Mutation } \\
\text { in a } B R C A \text { gene }\end{array}$} \\
\hline & & & & & & $\begin{array}{l}\text { Myriad } \\
\text { Prevalence } \\
\text { Tables (\%) }\end{array}$ & $\begin{array}{l}\text { Couch } \\
\text { Prediction } \\
\text { Model (\%) }\end{array}$ \\
\hline 1-RJ & Breast & 33 & MAT Br (F-45) & Yes & No & 16.3 & 20.0 \\
\hline 2-RJ & Ovarian & 47 & PAT Ov (60), Br (F-30), End (64) & Yes & No & 46.8 & 44.0 \\
\hline \multirow[t]{2}{*}{ 3-RS } & Ovarian & 52 & $\begin{array}{r}\text { MAT Br (F-44), Ov (F-76), Ov (F-66), Ut (F-78), Ut (N/A), } \\
\text { Ga (M-68), } \\
\text { CRC (M-69), HeN (M-N/A), HeN (M-75) }\end{array}$ & No & No & 46.8 & 43.0 \\
\hline & & & $\begin{array}{c}\text { PAT Lu (M-N/A), CRC (M-N/A), CRC (F-N/A), Ut (35), Br } \\
\text { (M-62), Ga (M-N/A), Br (F-36), Bilat Br (F-45), Br (F-44), Br } \\
\text { (F-45) }\end{array}$ & Yes & No & 40.8 & 33.0 \\
\hline 4-RJ & Bilateral Breast & 45 and 50 & MAT BilatBr (F-45,50), Ov (39) Br (F-49), Bilat Br (F-47,50) & Yes & No & 40.7 & 31.0 \\
\hline $5-R J$ & Bilateral Breast & 46 and 47 & PAT Lu (M-N/A), Ga (M-N/A) CRC (M-N/A) & No & Yes & 6.9 & 9.0 \\
\hline $6-R J$ & Bilateral Breast & 33 and 38 & - & No & Yes & 6.9 & 15.0 \\
\hline 7-RS & Bilateral Breast & 35 and 45 & $\begin{array}{c}\text { MAT Ov (F-58), Ov (F-49), Br (F-90) Br (F-49), Ga (M-70), } \\
\text { Liv (M-70) }\end{array}$ & Yes & No & 40.7 & 47.0 \\
\hline
\end{tabular}

Legend: RJ: family recruited from Rio de Janeiro; RS = family recruited from Porto Alegre;

$\left.{ }^{*}\right)$ MAT = cancer history in maternal side of the family, PAT = cancer history in paternal side of the family; other cancer diagnoses in family are indicated by the abbreviated cancer type $(\mathrm{Br}=$ breast, $\mathrm{Lu}=$ lung; $\mathrm{Ga}=$ gastric $\mathrm{Ov}=$ ovarian; Prost = prostate; Esoph = esophageal; Liv = liver; End = endometrial; $\mathrm{CRC}=$

Colorectal; HeN = head and neck cancer; Ut = uterine cancer, not defined whether cervix or endometrium) followed by followed by sex ( $\mathrm{M}=$ male, $\mathrm{F}=$ female) and age at diagnosis (N/A = not available). 
identification of a deleterious germline mutation in a cancer predisposition gene. In the case of the HBOC syndrome, genetic testing is often hampered by the complexity and cost of testing the $B R C A$ genes, especially in lower resource countries. In Brazil, such testing is not yet covered by private insurance nor provided by the public health care system and its cost in private laboratories precludes its use for most at-risk families.

The initial screening of founder mutations in BRCA1 and $B R C A 2$ before investigation of their entire coding regions has been well established in individuals of Ashkenazi Jewish ancestry as well as in a few other populations, and it is considered a cost-effective approach in these populations $[25,26]$. In other Latin American communities, this issue has not been largely explored. An exception is a large cohort of Latin American HBOC families studied by Weitzel et al. (2005) [27] in which six recurrent mutations in BRCA1 accounted for $47 \%$ of the deleterious germline mutations and interestingly, the BRCA1 c.68_69del mutation, one of the Ashkenazi Jewish founder mutations, occurred in $3.6 \%$ of this clinic-based cohort of predominantly Mexican women. In this study the authors suggest that an initial diagnostic screen with a panel for these more commonly observed mutations could be costeffective.

Only two reports from Brazilian breast-cancer affected patients have suggested that a founder BRCA1 mutation, c.5266dup, may be encountered at a significant prevalence $[16,17]$. This mutation is the second most common mutation described in the Breast Cancer Information Core (BIC) database [28] for HBOC families worldwide. It has been reported in $14.0 \%, 10.0 \%, 6.0 \%$ and $4.0 \%$ of Ashkenazi Jewish, German, Italian and Russian women with breast cancer [29-32], respectively. It was also described in a recent study from Portugal, where it appeared in approximately $1.0 \%$ of the series studied [33]. In addition, in a recent multi-national study, Hamel et al. (2011) [18] identified this mutation in several European countries. To our knowledge, it has not been detected in Spain [34,35] nor in other South American countries, although only a few comprehensive mutation studies (i.e. including sequencing of the entire coding region of both genes and gene rearrangement testing) in HBOC families have been produced in these regions [34-40]. The penetrance of the BRCA1c.5266dup mutation has been well defined in Ashkenazi women, being associated with a cumulative lifetime risk of 0.67 for breast cancer and 0.33 for ovarian cancer [41].

In the present study, we screened 137 unrelated and self-referred non-Ashkenazi women at high risk for the HBOC syndrome for the three common founder mutations described in Ashkenazi Jewish cohorts and only BRCA1c.5266dup was identified, at a frequency of 5.0\%. As expected, this frequency is higher than that described by the other Brazilian studies, including that of Gomes et al. [15] and Esteves et al [42], and likely results from the study design, that defined a significant personal and familial cancer history as inclusion criterion at recruitment.

Our results are in agreement with previous prevalence studies of the c.5266dup mutation in other high-risk nonAshkenazi populations, such as the Italian and German populations [30,31]. The origin of the BRCA1c.5266dup mutation in Brazilian patients and its relation to the Eastern-European counterpart remain to be determined. In a recently published study, da Costa et al. (2008) [43] evaluated the haplotypic profile of seven Brazilian carriers of c.5266dup and reported that all mutation carriers shared an identical haplotype, indicating a common origin. Some authors (i.e. Carvalho Silva et al. [44] and Gomes et al. [15]) have postulated that the entry of this mutation into Brazil is related to immigration of European Jews from Portugal in the sixteenth century. In the report by Weitzel et al. (2005) [27], that identified the Ashkenazi founder mutation c.68_69del in Mexican HBOC families, all mutation carriers shared the Ashkenazi Jewish founder haplotype. The authors postulate that Mexican carriers of these mutations are likely descendants of Conversos who immigrated to the Americas in the $15^{\text {th }}-16^{\text {th }}$ centuries and over generations assimilated into the larger Hispanic society. The same reasoning may be applied to the occurrence of BRCA1c.5266dup in Brazil. However, the absence of this mutation in studies from Spain or from other South American countries and the fact that only one case was reported in Portugal is against this hypothesis. Recent results from the study of Hamel et al. (2011) [18], show that the mutation probably originated in Scandinavia or Northern Russia, was then disseminated in European populations and thus could have entered Brazil through one or more of the several large European immigration waves in the $18^{\text {th }}$ and $19^{\text {th }}$ centuries. A detailed understanding of its entrance and distribution in Brazil, remains to be determined $[45,46]$.

One interesting finding of our study is the high frequency of the c.5266dup mutation in patients with bilateral breast cancer, compared to those with unilateral breast cancer. It is known that women with bilateral breast cancer are more likely to carry a $B R C A$ mutation [47,48]. Gershoni-Baruch et al. (1999) [49], studying Jewish women with bilateral breast cancer, found a high prevalence of founder mutations (31.0\%), and 3.7\% of the cases carried the c.5266dup mutation. In their report, bilateral breast cancer per se did not seem to reflect genetic predisposition unless associated with early age of onset. In another study that compared mutation prevalence in women with unilateral, family history positive and early onset breast cancer and women with bilateral breast cancer, the distribution of 
BRCA1c.5266dup was not significantly different between groups [32].

A limitation of our study is that we have not investigated the potential existence of other founder mutations that could become apparent after gene full gene sequencing; however, there is currently no published evidence for Brazilian BRCA founder mutations other than c.5266dup. We did not consider testing for founders described in Hispanic populations (i.e. Weitzel et al. (2005) [27]; Rodriguez et al. (2008) [50]) since it is our understanding that the population from the Brazilian cities studied here show trihybrid ancestries that are distinct from the Central American populations as indicated by studies from Alves-Silva et al. (2000) [51] and Parra et al. (2003) [52]. Additionally, it has been demonstrated clearly that even mestizos from different Central and South American regions have significant intra- and interethnic variability and admixture profiles [53].

Finally, a debatable point regarding founder mutation frequency in a given population or high risk group, is how much is enough to justify screening. Although the economic analysis of such a question is beyond the scope of our study, there must be also a concern with the social and medical consequences of such testing. Given current knowledge, if a recommendation for screening of founder $B R C A$ mutations is made for Brazilian HBOC women without subsequent comprehensive testing, most (likely > $90 \%$ ) of the mutations carriers would remain unidentified. Such a recommendation could be erroneously interpreted as sufficient, or result in false tranquilization whenever negative, hampering continuation towards mutation testing of the entire coding region of both genes, which could obviously have serious consequences for these individuals and their families. This concern is further justified by the inaccessibility to proper cancer genetic counseling for most high-risk Brazilian women, and by the lack of coverage through both private and public health-based insurance of germline mutation testing. Thus, although the frequency of one single mutation, BRCA1c.5266dup is significant in this subset of Brazilian women with a personal and familial history of HBOC, initial screening for one founder mutation in at-risk patients should be performed in the setting of genetic counseling and within a cancer risk evaluation program. In a high-risk patient or family, testing should always include a comprehensive approach (full gene sequencing and rearrangement testing for both $B R C A$ genes) when the initial founder mutation screening is negative.

We conclude that initial screening of the $B R C A 1$ c.5266dup mutation in Brazilian individuals at high risk for HBOC is justified, but should be considered with caution. This statement is based on the frequency of the single founder mutation currently described in this population, lack of evidence of other founder BRCA mutants at a significant frequency in Brazil, and potential consequences of misinterpretation of negative screening results. These principles may apply to other highly admixed populations in South America and other continents.

It is imperative to concentrate efforts in making $B R C A$ mutation testing and genetic counseling available to all high-risk patients in Brazil, and in educating health care professionals in the identification and proper management of these individuals. The best strategy for mutation screening and molecular diagnosis of high risk HBOC families in Brazil will only be fully understood after a comprehensive knowledge of BRCA mutation types and frequencies in this population.

Finally, the fact that two of the seven mutation-positive individuals had a limited family structure reinforce the importance of recognizing this feature and demonstrate that criteria for genetic testing must be adapted to consider this variable. The increased frequency of BRCA1c.5266dup in women with bilateral breast cancer should be further assessed in a larger cohort.

\section{Abbreviations}

ASCO: American Society of Clinical Oncology; BIC: Breast Cancer Information Core; BRCA1: Breast Cancer 1; BRCA2: Breast Cancer 2; CAPES: Coordenação de Aperfeiçoamento de Pessoal de Nível Superior; CNPq: Conselho Nacional de Desenvolvimento Científico e Tecnológico; FIPE - HCPA: Fundação de Incentivo à Pesquisa do Hospital de Clínicas de Porto Alegre; FAPERGS: Fundação de Amparo à Pesquisa no Rio Grande do Sul; HBOC: Hereditary Breast and Ovarian Cancer; PCR: Polymerase Chain Reaction; PRODOC:

Programa de Apoio a Projetos Institucionais com a Participação de Recém Doutores.

\section{Acknowledgements}

This study was supported in part by grants from Susan G. Komen for the Cure (POP\#0403033), Fundo de Incentivo à Pesquisa - FIPE, Hospital de Clínicas de Porto Alegre (\# 04-081), Rede Nacional de Câncer Familial - CNPq (021/2006) and Coordenação de Aperfeiçoamento de Pessoal de Nível Superior (CAPES - PRODOC Grant number 00202/03-7). P.A-P, MAMM, FRV and RG are investigators of CNPq, IPE received a Grant from CAPES and PI received a Grant from Fundação de Amparo à Pesquisa no Rio Grande do Sul (FAPERGS).

This work was supported also by a grant "Programa de Apoio a Núcleos de Excelência (PRONEX)" from FAPERGS, Brazil.

\section{Author details}

'Laboratório de Medicina Genômica, Centro de Pesquisa Experimental Hospital de Clínicas de Porto Alegre. Rua Ramiro Barcelos 2350. 90035-903. Porto Alegre, RS. Brazil. ${ }^{2}$ Programa de Pós-Graduação em Medicina: Ciências Médicas, Universidade Federal do Rio Grande do Sul. Rua Ramiro Barcelos 2400, $2^{\circ}$ andar. 90035-903. Porto Alegre, Brazil. ${ }^{3}$ Programa de Pós-Graduação em Genética de Biologia Molecular, Universidade Federal do Rio Grande do Sul. Av. Bento Gonçalves, 9500 - Prédio 43323M. 91501-970 - Caixa Postal 15053 - Porto Alegre, RS, Brasil. ${ }^{4}$ Departamento de Genética e Biologia Molecular, Centro de Ciências Biológicas e da Saúde, Universidade Federal do Estado do Rio de Janeiro. Rua Frei Caneca, 94. 20211-030 Rio de Janeiro, Brazil. ${ }^{5}$ Divisão de Genética, INCA (Instituto Nacional de Câncer). Rua André Cavalcanti, 37 - Centro 20231-050. Rio de Janeiro, Brazil. 'aboratório de Genômica Funcional e Bioinformática, Instituto Oswaldo Cruz (IOC-FIOCRUZ), Fundação Oswaldo Cruz, Av. Brasil 4365. Pavilhão Leônidas Deane (Pav. 26) $1^{\circ}$ andar- sala 110 21040-900 - Rio de Janeiro, Brazil. ${ }^{7}$ Departamento de Pediatria, Faculdade de Medicina da Universidade de São Paulo. Av. Dr. Enéas Carvalho de Aguiar 647. 05403-900, São Paulo, Brazil. ${ }^{8}$ Instituto Israelita 
de Ensino e Pesquisa Albert Einstein. Av. Albert Einstein 627, 05651-901. São Paulo, Brazil. ${ }^{9}$ Instituto de Matemática, Universidade Federal do Rio Grande do Sul. Av. Bento Gonçalves 9500 Prédio 43-111 - Agronomia. Caixa Postal 15080, Porto Alegre, Brazil. ${ }^{10}$ Núcleo Mama Moinhos. Associação Hospitalar Moinhos de Vento. Rua Ramiro Barcelos 910, 11‥ Andar. 90035-001, Porto Alegre, Brazil. ${ }^{11}$ Serviço de Genética Médica, Hospital de Clínicas de Porto Alegre. Rua Ramiro Barcelos 2350. 90035-903. Porto Alegre, RS. Brazil. ${ }^{12}$ Departamento de Genética, Universidade Federal do Rio Grande do Sul. Av. Bento Gonçalves, 9500 - Prédio 43323. Caixa Postal 15053 - 91501-970. Porto Alegre, Brazil. ${ }^{13}$ Instituto Nacional de Genética Médica Populacional INAGEMP. Hospital de Clínicas de Porto Alegre. Rua Ramiro Barcelos 2350. 90035-903. Porto Alegre, RS. Brazil.

\section{Authors' contributions}

IPE carried out the molecular genetic studies, sequencing analysis and drafted the manuscript. PI participated in data collection, data analysis and drafted the manuscript. FRV, MAMM and ASM participated in patient recruitment, data collection and revision of the manuscript. CAMF, DRC and SH participated in sequencing analysis. SAC contributed to study design, critical data analysis and coordinated statistical analyses. AS participated in statistical analyses. MC contributed to study design and participated in patient recruitment. PKS participated in sequencing analysis and critical data analysis. RG participated in supervision of IPE, drafting and revision of the manuscript. PAP conceived of the study and supervised data collection, molecular genetic studies, data analysis and manuscript revision. All authors read and approved the final manuscript.

\section{Competing interests}

The authors declare that they have no competing interests.

Received: 25 April 2011 Accepted: 20 December 2011

Published: 20 December 2011

\section{References}

1. Instituto Nacional do Cancer: Brazil 2011 [http://www.inca.gov.br].

2. Ashton-Prolla P, Palmero El, Roth FL: Mastologia: Genética e Câncer de Mama. In Ginecologia Baseada em Evidências.. 2 edition. Edited by: Silveira GPG. Atheneu; 2008:519-529.

3. Gonçalves ATC, Jobim PFC, Vanacor $R$, et al: Câncer de mama: mortalidade crescente na Região Sul do Brasil entre 1980 e 2002. Cadernos Saúde Pública 2007, 23:1785-1790.

4. Allain DC: Genetic counseling and testing for common hereditary breast cancer syndromes: a paper from the 2007 William Beaumont hospital symposium on molecular pathology. J Mol Diagn 2008, 10(5):383-95.

5. Online Mendelian Inheritance in Man. 2011 [http://omim.org/entry/ 113705].

6. Ford D, Easton DF, Bishop DT, Narod SA, et al: Risks of cancer in BRCA1 mutation carriers. Lancet 1994, 343:692-695.

7. Walsh T, Casadei S, Coats KH, et al: Spectrum of mutations in BRCA1, $B R C A 2, C H E K 2$, and TP53 in families at high risk of breast cancer. JAMA 2006, 295:1379-1388.

8. Tonin P, Weber B, Offit $K$, et al: Frequency of recurrent BRCA1 and BRCA2 mutations in Ashkenazi Jewish breast cancer families. Nat Med 1996, 2:1179-1183.

9. Warner E, Heisey RE, Goel V, et al: Hereditary breast cancer. Risk assessment of patients with a family history of breast cancer. Can Fam Physician 1999, 45:104-112.

10. Bogdanova NV, Rogov YI, et al: High frequency and allele-specific differences of BRCA1 founder mutations in breast cancer and ovarian cancer patients from Belarus. Clin Genet 2010, 78(4):364-72.

11. Uglanitsa N, Oszurek O, Uglanitsa K, et al: The contribution of founder mutations in BRCA1 to breast cancer in Belarus. J Clin Genet 2010 78(4):377-80.

12. Sarantaus $L$, Arason A, et al: Haplotype analysis in Icelandic and Finnish BRCA2999del5 breast cancer families. Eur J Hum Genet 2001, 9:773-779.

13. Hartmann $C$, John AL, Klaes $R$, et al: Large BRCA1 gene deletions are found in $3 \%$ of German high-risk breast cancer families. Hum Mutat 2004, 24(6):534.

14. Lawrence WF, Peshkin BN, Liang W, et al: Cost of Genetic Counseling and Testing for BRCA1 and BRCA2 Breast Cancer Susceptibility Mutations. Cancer Epidemiol Biomarkers Prev 2001, 10(5):475-481.
15. Gomes MC, Costa MM, Borojevic R, et al: Prevalence of $B R C A 1$ and $B R C A 2$ mutations in breast cancer patients from Brazil. Breast Cancer Res Treat 2007, 103(3):349-53.

16. Vargas FR, Bines J, et al: BRCA1 mutations in Brazilian patients. Genetics and Molecular Biology 2004, 27:500-504.

17. Simon SD, Molina A, Moreira-Filho CA: Mutations of BRCA1/2 genes in Brazil. ASCO Annual Meeting New Orleans, USA; 2003.

18. Hamel N, Feng BJ, Foretova $L$, et al: On the origin and diffusion of BRCA1c.5266dupC (5382insC) in European populations. Eur J Hum Genet 2011, 19(3):300-6.

19. ASCO Subcommittee on Genetic Testing for Cancer Susceptibility: Statement of the American Society of Clinical Oncology: Genetic Testing for Cancer Susceptibility. J Clin Oncol 1996, 14:1730-1736.

20. Frank TS, Deffenbaugh AM, Reid JE, et al: Clinical characteristics of individuals with germline mutations in BRCA1 and BRCA2: analysis of 10,000 individuals. J Clin Oncol 2002, 20:1480-1490.

21. Myriad Genetics, Laboratories and Pharmaceuticals, Inc: 2007 [http://www. myriad.com].

22. Couch Modified Mutation Prediction Model. 2011 [http://www.afcri. upenn.edu/itacc/penn2/].

23. Puregene genomic DNA purification method. 2011 [http://www1.qiagen. com/Products/GenomicDnaStabilizationPurification/ GentraPuregeneBloodKit].

24. Weitzel JN, Lagos VI, Cullinane CA, et al: Limited family structure and BRCA gene mutation status in single cases of breast cancer. JAMA 2007, 297(23):2587-2595

25. Abeliovich D, Kaduri L, Lerer I, et al: The founder mutations 185 delAG and 5382insC in BRCA1 and 6174delT in BRCA2 appear in 60\% of ovarian cancer and $30 \%$ of early-onset breast cancer patients among Ashkenazi women. Am J Hum Genet 1997, 60(3):505-514.

26. Jeffery P, Struewing MD, Hartge Patricia, et al: The Risk of Cancer Associated with Specific Mutations of BRCA1 and BRCA2 among Ashkenazi Jews. N Engl J Med 1997, 336:1401-1408.

27. Weitzel JN, Lagos V, Blazer KR, et al: Prevalence of BRCA mutations and founder effect in high-risk Hispanic families. Cancer Epidemiol Biomarkers Prev 2005, 14(7):1666-71.

28. Breast Cancer Information Core (BIC) database: 2011 [http://research.nhgri. nih.gov/bic/l.

29. Couch FJ, Weber BL: Mutations and polymorphisms in the familial earlyonset breast cancer (BRCA1) gene. Breast Cancer Information Core Hum Mutat 1996, 8:8-18.

30. Backe J, Hofferbert S, Skawran B, et al: Frequency of BRCA1 mutation 5382insC in German breast cancer patients. Gynecol Oncol 1999, 72:402-406.

31. Tommasi S, et al: BRCA1 mutations and polymorphisms in a hospitalbased consecutive series of breast cancer patients from Apulia, Italy. Mutat Res 2005, 578:395-405.

32. Sokolenko AP, Rozanov ME, Mitiushkina NV, et al: Founder mutations in early-onset, familial and bilateral breast cancer patients from Russia. Fam Cancer 2007, 6:281-286.

33. Peixoto A, Salgueiro N, Santos C, et al: BRCA1 and BRCA2 germline mutational spectrum and evidence for genetic anticipation in Portuguese breast/ovarian cancer families. Fam Cancer 2006, 5(4):379-387.

34. Esteban-Cardeñosa E, Bolufer Gilabert P, de Juan Jimenez I, et al: Broad $B R C A 1$ and $B R C A 2$ mutational spectrum and high incidence of recurrent and novel mutations in the eastern. Spain population. Breast Cancer Res Treat 2010, 121(1):257-60.

35. Diez O, Gutiérrez-Enríquez S, Balmaña J, et al: Heterogeneous prevalence of recurrent $B R C A 1$ and $B R C A 2$ mutations in Spain according to the geographical area: implications for genetic testing. Fam Cancer 2010, 187-91.

36. Llort $G$, Munoz CY, Tuser MP, et al: Low frequency of recurrent BRCA1 and BRCA2 mutations in Spain. Hum Mutat 2002, 19:307.

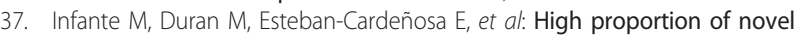
mutations of BRCA1 and BRCA2 in breast/ovarian cancer patients from Castilla-Leon (central Spain). J Hum Genet 2006, 51:611-617.

38. Jara $L$, Ampuero $S$, Santibánez $E$, et al: BRCA1 and BRCA2 mutations in a South American population. Cancer Genet Cytogenet 2006, 166:36-45.

39. Salazar R, Cruz-Hernandez JJ, Sanchez-Valdivieso E, et al: BRCA1-2 mutations in breast cancer: identification of nine new variants of BRCA1- 
2 genes in a population from central Western Spain. Cancer Lett 233:172-177.

40. Torres D, Rashid MU, Gil F, et al: High proportion of BRCA1/2 founder mutations in Hispanic breast/ovarian cancer families from Colombia. Breast Cancer Res Treat 2007, 103:225-232.

41. Antoniou AC, Pharoah PD, Narod S, et al: Breast and ovarian cancer risks to carriers of the BRCA1 5382insC and 185delAG and BRCA2 6174delT mutations: a combined analysis of 22 population based studies. J Med Genet 42:602-603.

42. Esteves VF, Thuler $L C$, Amêndola $L C$, et al: Prevalence of $B R C A 1$ and $B R C A 2$ gene mutations in families with medium and high risk of breast and ovarian cancer in Brazil. Braz J Med Biol Res 2009, 42(5):453-7.

43. da Costa EC, Vargas FR, Moreira AS, et al: Founder effect of the BRCA1 5382insC mutation in Brazilian patients with hereditary breast ovary cancer syndrome. Cancer Genet Cytogenet 2008, 184(1):62-66.

44. Carvalho-Silva DR, Santos FR, Rocha J, et al: The phylogeography of Brazilian Y-chromosome lineages. Hum Genet 2001, 68:281-286.

45. Cardeñosa E, Bolufer Gilabert P, de Juan Jimenez I, et al: BRCA1 and BRCA2 mutational spectrum and high incidence of recurrent and novel mutations in the eastern Spain population. Breast Cancer Res Treat 121(1):257-60.

46. Diez O, Gutiérrez-Enríquez S, Balmaña J: Heterogeneous prevalence of recurrent $B R C A 1$ and $B R C A 2$ mutations in Spain according to the geographical area:implications for genetic testing. Fam Cancer 2010, 9(2):187-91.

47. Loman $\mathrm{N}$, Johannsson $\mathrm{O}$, Kristoffersson $\mathrm{U}$, et al: Family history of breast and ovarian cancers and BRCA1 and BRCA2 mutations in a populationbased series of early-onset breast cancer. J Nat Can Inst 2003, 93(16):1215-1223.

48. Weitzel JN, Robson M, Pasini B, et al: A comparison of bilateral breast cancers in BRCA carriers. Can Epid Bio Prev 2004, 14(6):1534-1537.

49. Gershani-Baruch R, Dagan E, Fried G, et al: BRCA1 and BRCA2 founder mutations in patients with bilateral breast cancer. Eur J HumGenet 1999, 7:833-836

50. Rodriguez RC, Esperon AA, Ropero R, et al: Prevalence of $B R C A 1$ and BRCA2 mutations in breast cancer patients from Cuba. Fam Cancer 2008, 7:275-279.

51. Alves-Silva J, da Silva Santos M, Guimaraes PE, et al: The ancestry of Brazilian mt DNA lineages. Am J Hum Genet 67:444-461.

52. Parra FC, Amado RC, Lambertucci JR, et al: Color and genomic ancestry in Brazilians. Proc Natl Acad Sci USA 2003, 100:177-182.

53. Wang $S$, Lewis $C M$, Jakobsson $M$, et al: Genetic variation and population structure in native Americans. PLoS Genet 2007, 3(11):e185.

doi:10.1186/1897-4287-9-12

Cite this article as: Ewald et al.: Prevalence of the BRCA1 founder mutation c.5266dupin Brazilian individuals at-risk for the hereditary breast and ovarian cancer syndrome. Hereditary Cancer in Clinical Practice 2011 9:12.

\section{Submit your next manuscript to BioMed Central and take full advantage of:}

- Convenient online submission

- Thorough peer review

- No space constraints or color figure charges

- Immediate publication on acceptance

- Inclusion in PubMed, CAS, Scopus and Google Scholar

- Research which is freely available for redistribution

Submit your manuscript at www.biomedcentral.com/submit
Ciomed Central 